\title{
Coupling of urban energy balance model with 3-D radiation model to derive human thermal (dis)comfort
}

\author{
Sandro M. Oswald ${ }^{1}$ (1) - Michael Revesz ${ }^{2}$. Heidelinde Trimmel ${ }^{1}$ - Philipp Weihs ${ }^{1}$ - Shokufeh Zamini ${ }^{2}$. \\ Astrid Schneider ${ }^{2}$. Martin Peyerl ${ }^{3}$. Stefan Krispel ${ }^{3}$. Harald E. Rieder ${ }^{4}$. Erich Mursch-Radlgruber ${ }^{1}$. \\ Fredrik Lindberg ${ }^{5}$
}

Received: 11 May 2018 / Revised: 24 September 2018 / Accepted: 28 October 2018 / Published online: 5 December 2018 (C) The Author(s) 2019

\begin{abstract}
While capabilities in urban climate modeling have substantially increased in recent decades, the interdependency of changes in environmental surface properties and human (dis)comfort have only recently received attention. The open-source solar long-wave environmental irradiance geometry (SOLWEIG) model is one of the state-of-the-art models frequently used for urban (micro-)climatic studies. Here, we present updated calculation schemes for SOLWEIG allowing the improved prediction of surface temperatures (wall and ground). We illustrate that parameterizations based on measurements of global radiation on a south-facing vertical plane obtain better results compared to those based on solar elevation. Due to the limited number of ground surface temperature parameterizations in SOLWEIG, we implement the two-layer force-restore method for calculating ground temperature for various soil conditions. To characterize changes in urban canyon air temperature $\left(T_{c a n}\right)$, we couple the calculation method as used in the Town Energy Balance (TEB) model. Comparison of model results and observations (obtained during field campaigns) indicates a good agreement between modeled and measured $T_{c a n}$, with an explained variance of $R^{2}=0.99$. Finally, we implement an energy balance model for vertically mounted PV modules to contrast different urban surface properties. Specifically, we consider (i) an environment comprising dark asphalt and a glass facade and (ii) an environment comprising bright concrete and a PV facade. The model results show a substantially decreased $T_{\text {can }}$ (by up to $-1.65^{\circ} \mathrm{C}$ ) for the latter case, indicating the potential of partially reducing/mitigating urban heat island effects.
\end{abstract}

Keywords SOLWEIG $\cdot$ PV energy balance $\cdot$ Surface temperature parameterization $\cdot$ UTCI

Electronic supplementary material The online version of this article (https://doi.org/10.1007/s00484-018-1642-z) contains supplementary material, which is available to authorized users.

Sandro M. Oswald

sandro.oswald@boku.ac.at

1 Institute of Meteorology, University of Natural Resources and Life Sciences (BOKU), Vienna, Austria

2 AIT Austrian Institute of Technology GmbH, Vienna, Austria

3 Smart Minerals GmbH, Vienna, Austria

4 Wegener Center for Climate and Global Change and IGAM/Institute of Physics, University of Graz, Graz, Austria

5 Department of Earth Sciences, University of Gothenburg, Gothenburg, Sweden

\section{Introduction}

Today about half of the world's population resides in urban areas. Future projections show pronounced urbanization rates and it is expected that by 2050, about two thirds of the world's population will be urban (UN 2014). Several studies report on increased thermal heat stress in urban microclimates, e.g., Grimmond et al. (2010). In order to adapt to climate change, some countries aim to reduce solar absorption in urban environments by maximizing the area of highly reflective surfaces through installation of the socalled white roofs. Also, at a time where sustainable energy production becomes more and more important, "solar cities" aim on maximizing "solar harvest", i.e., the solar yield from photovoltaic (PV) modules, by directing their roofs and 
facades towards the sun to avoiding shadowing. Reflections from the ground and surrounding buildings cause an increase of the solar radiation directed to the PV module, thus increased PV yield (Kotak et al. 2015; Lindberg et al. 2015). The role of PV modules in a city or as a facade in an urban canyon was discussed in the work of Brito et al. (2017). This study has shown that for specific study areas, the non-baseload electricity demand can be satisfied by costeffective PV investments on roofs and facades at today's market conditions for up to 10 months of the year. Further, winter mid-day electricity demand can only be achieved if the solar yield of PV facades is taken into account.

In terms of human thermal stress, this increase in reflection can cause more discomfort. Human (dis)comfort is commonly described by various bioclimatic indices. The Universal Thermal Climate Index (UTCI) (Fiala et al. 2001; Bröde et al. 2011; Blazejczyk et al. 2011) aggregates many of these in one standardized metric. The UTCI is based on complex multi-node thermophysiological models and allows to predict whole body thermal effects (e.g., hypothermia and hyperthermia; heat and cold discomfort) as well as localized effects (e.g., frostbite). Thereby, UTCI allows addressing all kinds of thermal stress and discomfort (e.g., extreme cold or warm) as well as conditions in which the human heat balance and the perceived outdoor temperature are affected by solar radiation. The accuracy of UTCI depends on a suite of input parameters; among these, especially a precise calculation of the mean radiant temperature $T_{m r t}$ is of uttermost importance (Weihs et al. 2011).

To provide $T_{m r t}$ with highest accuracy, we employ here an updated version (see below) of the opensource solar long-wave environmental irradiance geometry (SOLWEIG) model which is a part of the urban multiscale environmental predictor (UMEP) (Lindberg et al. 2018). SOLWEIG is a state-of-the-art model which combines building and vegetation surface models and spatial variations of 3-D radiative fluxes in complex urban settings. SOLWEIG has been extensively evaluated in urban environments over the last decade (Lindberg et al. 2008; Lindberg and Grimmond 2011; Lindberg et al. 2016).

In its present configuration (Lindberg and Grimmond 2016), SOLWEIG uses only observed ambient air temperature, independent of its measurement height, to estimate the temperatures of surrounding surfaces (i.e., wall and ground temperature) via a simple parameterization scheme. Moreover, according to the authors' knowledge, to date, no evaluation and simulation tools are available for urban areas, which can estimate the effects of a broad rollout of photovoltaic facade and different ground surfaces in urban districts necessary to characterize the change of ambient air temperature and in general microclimate in urban street canyons.
This study aims on closing this gap by coupling SOLWEIG with parts of the Town Energy Balance (TEB) model (Masson 2000). Below, we detail the model setup as well as results from a recent field campaign for model evaluation. During this field campaign, measurements of short-wave radiation, wind speed, air, and surface temperatures were performed. The campaign took place between August 2016 and September 2017 on the campus of the University of Natural Resources and Life Sciences (BOKU) in Vienna.

The study focuses on (i) the simulation of canyon air temperature based on measured input parameters and its comparison to observed canyon air temperature in the study domain (see dashed yellow box in Figure S1 in the supplemental material); and (ii) evaluating the impact of potential changes in the surface structure parameters of wall and ground (i.e., albedo and energy balance of the PV module) on the canyon air temperature and human comfort.

\section{Methods}

Based on the standard meteorological input file of SOLWEIG, we developed a model structure which uses only the required and available variables (ambient air temperature $T_{a}$, wind speed $U$, relative humidity $R H$, barometric pressure $p_{a}$, and incoming short-wave global radiation $G_{h}$ on a horizontal plane).

\section{Instrumentations}

For model development and evaluation, measurements which are routinely performed at the meteorological monitoring platform located at the rooftop of the SchwackhöferHaus (at approximately 26-m height above ground) have been used. Additional measurements have been performed within a street canyon nearby (southward-orientated at $3 \mathrm{~m}$ above ground). Figure 1a and $\mathrm{b}$ shows both platforms and the related measurements; Figure S1 in the supplemental material shows the measurement sites from the top (dark green ellipse $=$ rooftop, green point $=$ canyon) . During the campaign, radiation measurements were performed with two types of pyranometer: on the rooftop with a MS-802 global radiation pyranometer (EKO Instruments) with a wavelength range of $285-3000 \mathrm{~nm}$; in the urban canyon with a vertically mounted EMS 11 silicone diode sensor (EMS Brno) covering a wavelength range of 400-1100 nm. The ambient air temperature and relative humidity at the rooftop have been measured with a thermocouple type $\mathrm{K}$ combined with a humidity sensor (inside a radiation shield) in direct vicinity to the wind sensor (for speed and direction) on the rooftop (see Fig. 1a). Air temperature and wind speed measurements in the canyon were performed with a 


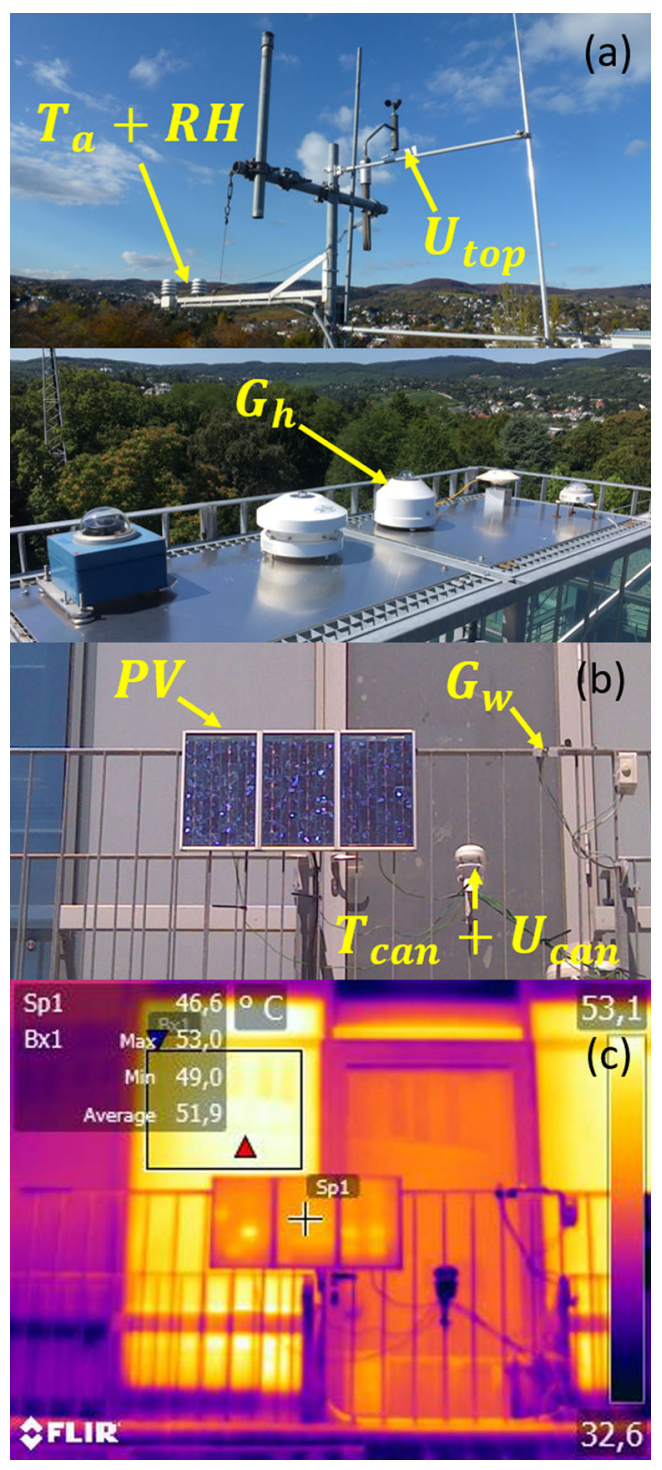

Fig. 1 Measurement setup used in this study. a The observational platform of the University of Natural Resources and Life Sciences (BOKU), located at the rooftop of the Schwackhöfer-Haus. b Additional instrumentation in the studied urban canyon. c Infrared picture of the setup shown in b taken on 19 June 2017 at 11:12 UTC. The acronyms in $\mathbf{a}$ and $\mathbf{b}$ indicate individual meteorological variables obtained; arrows point towards the corresponding instrument/sensor. These are ambient air temperature $T_{a}$ and relative humidity $R H$; both measured with a thermocouple located $26 \mathrm{~m}$ above ground; wind speed $U_{\text {top }}$ at the rooftop, measured with a Kroneis anemometer $27 \mathrm{~m}$ above ground; horizontal global radiation $G_{h}$, obtained with a MS-802 pyranometer (EKO Instruments); global radiation on a south-oriented vertical plane $G_{w}$ in the urban canyon, obtained with an EMS 11 global radiation silicone diode sensor (EMS Brno); canyon air temperature $T_{c a n}$ and canyon wind speed $U_{c a n}$, both obtained with a DS-2 sonic anemometer (METER Group, Inc). The three photovoltaic modules $P V$ are of type SX10M (SOLAREX). In the upper left of panel c, surface temperatures of the PV modules (Sp1) and the building facade of the Schwackhöfer-Haus (Bx1) are given

DS-2 sonic anemometer (METER Group, Inc.) with a speed range of $0-30 \mathrm{~m} \mathrm{~s}^{-1}$ and an accuracy of $0.3 \mathrm{~m} \mathrm{~s}^{-1}$ (see
Fig. 1b). The measurement outputs of the individual sensors in the urban canyon have been aggregated to 10-min averages to match the temporal resolution of the routine rooftop measurements.

The surface temperatures were additionally measured with an infrared camera of type FLIR E60bx (FLIR Systems), which has an accuracy of $\pm 2 \%$ between 0 and $650{ }^{\circ} \mathrm{C}$ (see Fig. 1c).

The potential electricity production inside the urban canyon was determined with three PV modules of type SX10m (SOLAREX). The surface temperature was measured with three thermocouples on the back side of the PV modules.

\section{Parameterization of wall surface temperature}

Bogren et al. (2000) proposes to estimate the surface temperatures $T_{S}$ (horizontal or vertical) via a linear relationship between maximum solar elevation and the maximum difference between measured $T_{a}$ and $T_{s}$ under clear-sky conditions (Lindberg et al. 2008). Here, we propose a different approach, using global radiation measured on a south-oriented vertical plane $G_{w}$ instead of solar elevation. $G_{w}$ is calculated as

$G_{w}=G_{h} \frac{\sin (\alpha+\beta)}{\sin (\alpha)}$

where $\beta$ is the tilt angle of the vertical plane measured from the horizontal and $\alpha$ is a function of the geographical latitude $\phi$ and the declination angle $\delta$ given by

$$
\begin{aligned}
\delta= & (180 / \pi) \cdot(0.006918-0.399912 \cdot \cos (B) \\
& +0.070257 \cdot \sin (B)-0.006758 \cdot \cos (2 B) \\
& +0.000907 \cdot \sin (2 B)-0.002697 \cdot \cos (3 B) \\
& +0.00148 \cdot \sin (3 B)), \\
\alpha= & 90-\phi-\delta
\end{aligned}
$$

where $B=(n-1) \frac{360}{365}$ with the $n$th day of the year (Spencer 1971; PVEducation 2017).

To obtain the wall surface temperature $T_{w}$, we apply the amplitude from the before mentioned linear relationship to a sinusoidal wave function with maximum temperature difference at 15:00 (local time) (Lindberg et al. 2016).

\section{Parameterization of ground surface temperature}

To calculate the ground temperature $T_{g}$, we apply the forcerestore method following Blackadar (1976) with a two-layer approximation, i.e., with a parameterization of the sensible heat flux $H_{s}$ (2nd term in Eq. 4) and the ground heat flux 
$H_{g}$ (3rd term in Eq. 4). The change in $T_{g}$ per time step is given as:

$\frac{\partial T_{g}}{\partial t}=\frac{F}{S z_{g}}-a_{F R}\left(T_{g}-T_{a s}\right)-\Omega\left(T_{g}-T_{m}\right)$

Here, $F$ represents the net radiation balance at the ground surface (which can be directly calculated with SOLWEIG), $S$ is the soil heat capacity given as a product of a materials density $\rho$ and its specific heat capacity $c, \Omega$ is the angle velocity of the Earth, and $a_{F R}$ which is a timeof-day dependent factor $\left(3 \times 10^{-4} \mathrm{~s}^{-1}\right.$ for daytime, $1 \times 10^{-4} \mathrm{~s}^{-1}$ for nighttime). $T_{m}$ is the approximately constant temperature of the bottom slab. The depth of the thermal active layer $z_{g}$ is calculated using time period $\tau$ and thermal conductivity $\lambda$ (Stull 1988):

$z_{g}=\sqrt{\frac{\tau \lambda}{4 \pi S}}$

It follows that the near-surface air temperature $T_{a s}$ has to be simulated based on measurements of $T_{a}$ on the rooftop. To model such continuous time series of $T_{g}$ at time step $(t+1)$, we apply the Euler method with a given $T_{g}$ at time step $(t)$ and the rate of change from Eq. 4 times a value $i$ for the size of every step:

$T_{g}(t+1)=T_{g}(t)+\frac{\partial T_{g}}{\partial t} \cdot i$

\section{Parameterization of urban canyon air temperature}

As detailed above, we are interested in the air temperature near the ground surface $T_{a s}$. For simplification, we set $T_{a s}$ as $\widehat{T}_{c a n}$ which is calculated in analogy to the TEB model.

$\widehat{T}_{\text {can }}=\frac{\frac{T_{g}}{R E S_{g}}+\frac{2 h}{w} \frac{T_{w}}{R E S_{w}}+\frac{T_{a}}{R E S_{\text {top }}}}{\frac{1}{R E S_{g}}+\frac{2 h}{w} \frac{1}{R E S_{w}}+\frac{1}{R E S_{\text {top }}}}$

Note we did not parameterize the anthropogenic sensible heat flux and snow cover terms given the general lack of traffic at the case study site and summer time conditions. Further required terms for estimating $\widehat{T}_{\text {can }}$ are $\frac{h}{w}$, the canyon aspect ratio (building height $h$ to street width $w$ ) and $R E S$, the aerodynamic resistance for the ground $\left(R E S_{g}\right)$, wall $\left(R E S_{w}\right)$, and rooftop $\left(R E S_{\text {top }}\right)$, respectively, given as:

$$
\begin{gathered}
R E S_{g}=R E S_{w}=\frac{c_{p} \rho_{a}}{\left(11.8+4.2 \sqrt{U_{c a n}^{2}+\left(u_{*}+w_{*}\right)^{2}}\right)} \\
R E S_{\text {top }}=\left(U_{\text {top }} C_{d}\right)^{-1}
\end{gathered}
$$

whereby $U_{c a n}$ (parameterized as in the TEB model) and $U_{\text {top }}$ (measured) are the wind speeds for canyon and rooftop, respectively. The characteristic scale of turbulent wind $u_{*}+w_{*}$ is calculated using $T_{a}, U_{t o p}$, and the drag coefficient $C_{d}$ (computed with the roughness length $z_{0_{\text {town }}}=\frac{h}{10}$ and $\widehat{T}_{\text {can }}$ of the previous time step) (Moigne
2012). For estimating the surface heat flux, we consider the rate of warming $\left(\frac{\partial T_{a}}{\partial t}\right)_{r}$ at the rooftop as representative for the whole convective boundary layer:

$u_{*}+w_{*}=\sqrt{C_{d}} U_{t o p}+\left[\frac{g h^{2}}{T_{a}}\left(\frac{\partial T_{a}}{\partial t}\right)_{r}\right]^{1 / 3}$

where $g$ is the gravitational constant (Arya 2001).

\section{Energy balance model for PV modules}

Following the concept of the heat dynamics model for building-integrated photovoltaic (BIPV) systems of Lodi et al. (2012), we introduce a modified energy balance model for PV module(s) mounted in urban canyons. As model input, we use besides global radiation information (see above) the measured surface temperature on the back side of the PV module $T_{b_{P V}}$, and information from a 2-D sonic anemometer. At our study site, the thermal radiative heat transfer between the back side of the PV module and the gray glass facade of the Schwackhöfer-Haus (see Fig. 1b) behind can be calculated following:

$Q l_{b}=\frac{A_{P V} \sigma}{\frac{1}{\varepsilon_{b_{P V}}}+\frac{1}{\varepsilon_{w}}-1}\left(T_{b_{P V}}^{4}-T_{w}^{4}\right)$

where $A_{P V}$ represents the area of the photovoltaic module with a value of $0.11 \mathrm{~m}^{2} . \varepsilon_{b_{P V}}$ and $\varepsilon_{w}$ are the emissivity for the back side of PV modules and the facade of the Schwackhöfer-Haus, respectively. $T_{P V}$, the front temperature of the PV module (which might be higher than $T_{b_{P V}}$ ), can be calculated following:

$T_{P V}=T_{b_{P V}}+\frac{G_{w}}{1000 \mathrm{~W} \mathrm{~m}^{-2}} \Delta T$

where $\Delta T$ is the temperature difference between the front and back sides of the PV module. $\Delta T$ is set to $1.9^{\circ} \mathrm{C}$ at an irradiance level of $1000 \mathrm{~W} \mathrm{~m}^{-2}$ (King et al. 2004).

Now, the long-wave radiation exchange $Q l_{f}$ between the sky, ground, the opposite building (Exner-Haus, see Figure S1 in the supplemental material), and the front side of the PV module is given as:

$$
\begin{aligned}
Q l_{f}= & A_{P V} \sigma\left(\Psi_{s k y} \varepsilon_{c} T_{s k y}^{4}+\Psi_{g} \varepsilon_{c} T_{g}^{4}\right. \\
& \left.+\Psi_{b} \varepsilon_{c} T_{b}^{4}-\varepsilon_{g l} T_{P V}^{4}\right)
\end{aligned}
$$

The parameter $\Psi$ is the view factor for surrounding surfaces. Figure S2 in the supplemental material shows a fisheye lens picture of the PV module perspective combined with three digitalized images for the sky, for the ground, and for buildings. The respective area percentage calculation yields a sky view factor of $\Psi_{s k y}=0.23$, ground view factor $\Psi_{g}=$ 0.43 , and a building's view factor of $\Psi_{b}=0.35$. For the emissivity $\varepsilon_{c}$, we assume a combined value of 0.95 . Due to the available information of dew point temperature $T_{\text {dew }}$ on 
the rooftop, the sky temperature $T_{s k y}$ can be calculated using the method of Duffie and Beckman (2013). The temperature of the Exner-Haus $T_{b}$, which is shaded throughout the day, is set to $T_{a}$ (Lindberg and Grimmond 2011).

To determine the convective heat transfer $Q c$ between the front (Eq. 14) and back sides (Eq. 15) of the PV module and the surrounding air, we apply Newton's law of cooling following Palyvos (2008) and Sharples (1984):

$$
\begin{aligned}
Q c_{f} & =A_{P V}\left(7.35+3.75 \cdot U_{c a n}\right)\left(T_{c a n}-T_{P V}\right), \\
Q c_{b} & =A_{P V}\left(1.8+1.93 \cdot U_{c a n}\right)\left(T_{c a n}-T_{b_{P V}}\right)
\end{aligned}
$$

The absorbed solar radiation is estimated through the transmittance-absorptance product $(\tau \alpha)_{P V} \cong 1.01 \tau_{g l} \alpha_{P V}$ (Duffie and Beckman 2013) and the incidence angle modifier IAM $\left(\theta_{a o i}\right)$ (Barker and Norton 2003):

$$
Q_{s}=A_{P V} 1.01 \tau_{g l} \alpha_{P V} G_{w} \operatorname{IAM}\left(\theta_{a o i}\right)
$$

The remaining term of the heat transfer process is transformed solar energy (i.e., electricity production of the $\mathrm{PV}$ module), which is given as a function of $T_{P V}$ :

$$
Q_{e}=A_{P V} G_{w} \operatorname{IAM}\left(\theta_{a o i}\right) \eta_{r e f}\left[1-\beta_{0}\left(T_{P V}-T_{P V, r e f}\right)\right]
$$

where $\eta_{r e f}$ is the reference PV module efficiency (determined by laboratory measurements), $\beta_{0}$ is a temperature coefficient (see Table 1), and $T_{P V, \text { ref }}=25^{\circ} \mathrm{C}$ is the reference temperature at $1000 \mathrm{~W} \mathrm{~m}^{-2}$ (manufacturer provided).

\section{Continuous Time Stochastic Modeling for unknown parameters}

Continuous Time Stochastic Modeling (CTSM) is widely used to estimate unknown parameters of non-linear systems (Jazwinski 1970; Nielsen et al. 2000). Following the scheme of a gray box model, which combines prior physical knowledge and information from measurements, one can use a set of stochastic differential equations (SDEs) of form

$d X_{t}=f\left(X_{t}, U_{t}, t, \Theta\right) d t+W\left(X_{t}, U_{t}, \Theta\right) d \omega_{t}$

and a set of discrete time observation equations of form

$y_{k}=M\left(X_{k}, U_{k}, t_{k}, \Theta\right)+e_{k}$

where $t$ is the time, $X_{t}$ is a vector of state variables, $U_{t}$ is a vector of input variables, $\Theta$ is a vector of unknown parameters, and $y_{k}$ is a vector of output variables. $f(\cdot)$, $W(\cdot)$, and $H(\cdot)$ are non-linear functions, $\omega_{t}$ is a Wiener process, and $e_{k}$ is the Gaussian white noise with the covariance $\sum_{t}$. The CTSM package in $\mathrm{R}$ (Juhl 2016) applies a maximum likelihood estimation of a time series with joint probability density function

$L(\Theta)=\left(\prod_{k=1}^{\mathrm{N}} p\left(y_{k} \mid \Upsilon_{k-1}, \Theta\right)\right) p\left(y_{0} \mid \Theta\right)$

with $\Upsilon_{\mathrm{N}}=\left[y_{0}, y_{1}, \ldots, y_{k}, \ldots, y_{\mathrm{N}}\right]$ as a time series of $N$ observations. CTSM-R computes the likelihood function and uses an optimization method to locate the most probable set of parameters (Juhl et al. 2016).

Given the relatively small area of the PV module used in this study (compared to, e.g., modules used in Jones and Underwood (2001) and Lodi et al. (2012)), we considered a single-state model to predict the average cell temperature. In our case, the unknown parameters are the absorptivity of the cells inside PV modules $\alpha_{P V}$ and the heat capacity $C_{P V}$. The non-linear system for the photovoltaic energy balance model to estimate these parameters is given as:

$$
\begin{aligned}
d T_{P V}= & C_{P V}^{-1}\left(Q c_{f}+Q c_{b}+Q l_{f}\right. \\
& \left.+Q l_{b}+Q_{s}-Q_{e}\right) d t+W d \omega_{t}, \\
T_{P V, m}= & T_{P V}+e_{k}
\end{aligned}
$$

Once the unknown parameters are determined, the Euler method from Eq. 6 can be used to calculate the estimated PV module temperature $\widehat{T}_{P V}(i)$ based on knowledge of global radiation (on a vertical plane), wind speed, and ambient air temperature at the rooftop, the angle of incidence of the current step $(i)$, and the back-side PV module temperature with the canyon air temperature from the previous time step $(i-1)$.

\section{Results}

\section{Model evaluation for wall, ground, and air temperature}

As shown in Lindberg et al. (2016), the surface temperature parameterization in SOLWEIG affects the mean radiant temperature. Thus, precise measurements of the temperature of surrounding surfaces are needed to accurately simulate the canyon air temperature.

To this aim, infrared measurements (with a FLIR E60bx) were taken of the facade behind the PV modules around the time of maximum solar elevation. Due to the possible settings in FLIR Tools (FLIR Systems 2016), the position where pictures were taken was $5 \mathrm{~m}$ in front looking normal to the wall of the Schwackhöfer-Haus and the emissivity was set to $\varepsilon_{w}=0.95$.

Following Lindberg et al. (2016), we show in Fig. 2a the difference in wall surface temperature $T_{w}$ and air (in our case canyon) temperature $T_{c a n}$, as a function of the maximum solar elevation. The regression coefficients found 


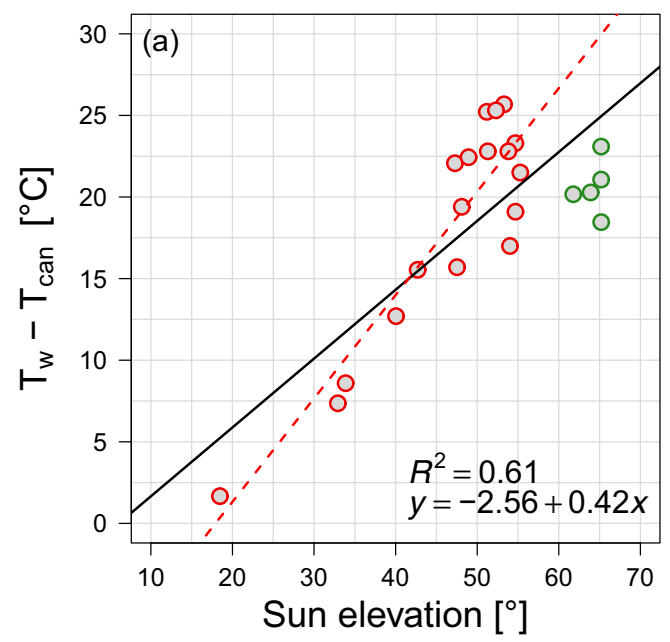

Fig. 2 Scatter plots of the difference in temperature between the wall surface temperature $\left(T_{w}\right)$ and canyon air temperature $\left(T_{c a n}\right)$ as a function of $\mathbf{a}$ the solar elevation and $\mathbf{b}$ global radiation on a south-facing vertical wall $\left(G_{w}\right)$. The green points in panel a mark the outliers from the theoretical curve (dashed red line) describing higher surface

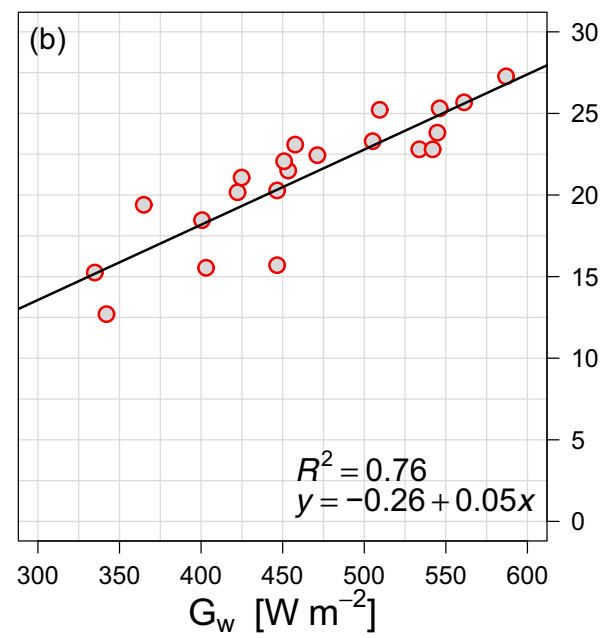

temperature at higher solar elevation. The squared Pearson correlation coefficient $\left(R^{2}\right)$ and the regression analysis with the coefficients are provided in each panel. Note the number of measurements in $\mathbf{a}$ and b are not the same as global radiation measurements have not been available on 2 days

parameters for the calculation of the canyon air temperature $\widehat{T}_{c a n}$ are available, we derive it following Eq. 7.

Figure 3 provides a time series of the measured and simulated air temperature inside and above the urban canyon. We show the estimates for $\widehat{T}_{\text {can }}$ for both the currently implemented SOLWEIG scheme (CS) and the here proposed calculation scheme (PS). While both, CS and PS agree quite well with the measurements of $T_{c a n}$, a closer comparison reveals structural differences among the two approaches. Estimates from CS agree closer with observations during morning hours (before 10:00 UTC), while estimates from PS are closer to the measured canyon air temperature around noon and during the afternoon/early evening (until about 19:00 UTC). A disadvantage of CS compared to PS is the circumstance that the ground temperature decreases immediately to $T_{a}$ due to the shadow matrix. This is clearly visible in Figure S4 (supplemental material) where at around 14:00 UTC, $T_{\text {asphalt }}(\mathrm{CS})$ rapidly decreases due to shading of the canyon (by the bridge marked with yellow lines in Figure S1). The two outliers in CS between 18:00 and 20:00 UTC stem from the fractional cloud cover function as described in Lindberg et al. (2008). Due to application of the parameterization throughout the night, the simulated air temperatures are too low, especially at the end of the time series after a pronounced heat wave.

The statistical analysis of the modeled versus observed canyon air temperature for CS and PS is shown in Fig. 4a and $b$, respectively. While both parameterization schemes work generally well, PS shows an improved explained variance (squared Spearman's rank correlation coefficient) compared to CS. More importantly though, the root mean 
Fig. 3 Time series of the air temperature $(T)$ measured at the rooftop $\left(T_{a}\right.$, red $)$ and inside the urban canyon ( $T_{c a n}$, green), and simulated canyon air temperature with the currently implemented SOLWEIG scheme (CS) ( $\widehat{T}_{\text {can }}$, orange, dashed line) and the proposed calculation scheme (PS) $\left(\widehat{T}_{c a n}\right.$, orange, solid line). Time series of the difference between $T_{\text {can }}$ and $\widehat{T}_{c a n}$, respectively, is shown in the lower part (brown dashed (CS) and solid (PS) lines)

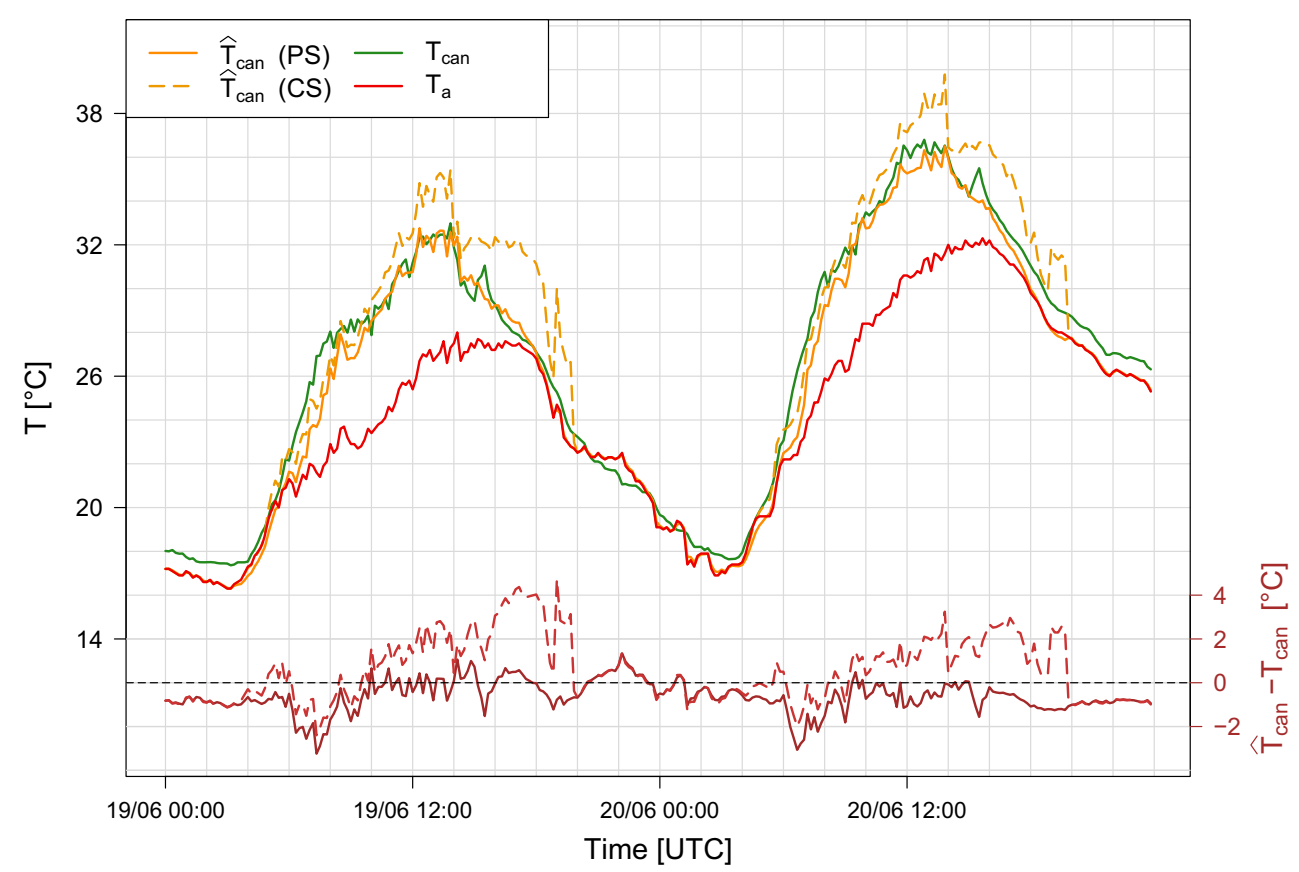

square error (RMSE) for PS is reduced compared to CS. In summary, the here-presented calculation scheme (PS) performs better than the standard scheme (CS). Nevertheless, also PS shows slight underestimations in the heating phase of the urban canyon.

\section{Parameter estimation and simulation for PV modules}

As manufacturers commonly do not provide optical or thermal specifications of a PV module, this information was compiled through literature review (see Table 1). The initial value of $C_{P V}$ for the CTSM system was estimated using a value given in Jones and Underwood (2001) with a total heat capacity of $2918 \mathrm{~J} \mathrm{~K}^{-1}$ and a total area of $0.51 \mathrm{~m}^{2}$. Assuming the mounted PV modules are very similar to the ones in Jones and Underwood (2001), the heat capacity of each module is $2918 \mathrm{~J} \mathrm{~K}^{-1} \cdot \frac{0.11 \mathrm{~m}^{2}}{0.51 \mathrm{~m}^{2}} \approx 650 \mathrm{~J} \mathrm{~K}^{-1}$ (scaled by total area). The final value of $C_{P V}$ is given in Table 1 . $\alpha_{P V}$ was also estimated by CTSM using an initial value of Moralejo-Vázquez et al. (2015).

Lodi et al. (2012) suggests parameter estimation based on data from partly cloudy days, given that the modeled heat transfer processes are less correlated under cloudy than under clear-sky conditions. For the present study, parameter estimation is based on data taken on 18 June 2017 between
Fig. 4 Scatter plots of measured $\left(T_{c a n}\right)$ and simulated $\left(\widehat{T}_{c a n}\right)$ canyon air temperature for $\mathbf{a}$ the proposed calculation scheme and $\mathbf{b}$ the currently implemented SOLWEIG scheme. Each panel provides the squared Spearman's rank correlation coefficient $\left(R^{2}\right)$ and the root mean square error (RMSE)
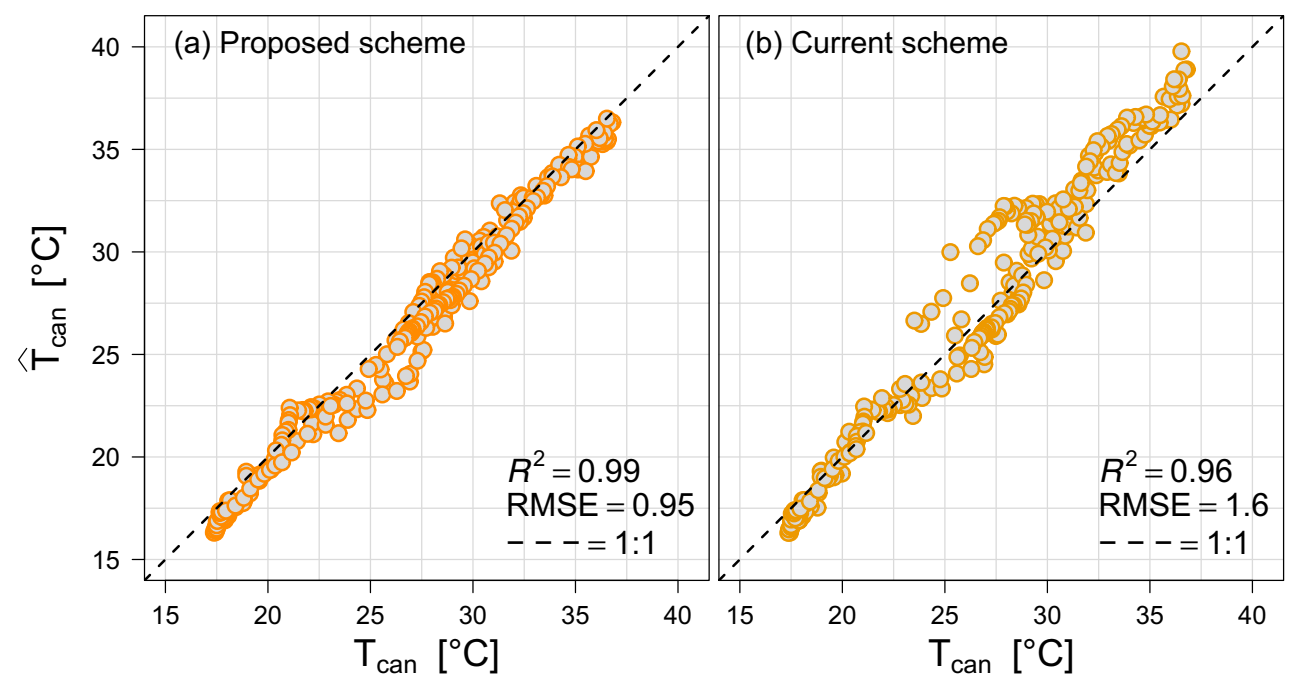
Fig. 5 a The auto-correlation function (ACF) and $\mathbf{b}$ the cumulated periodogram of the residuals for the continuous time stochastic model used for the mounted photovoltaic module. The blue dashed lines mark the $95 \%$ confidence limits for random noise
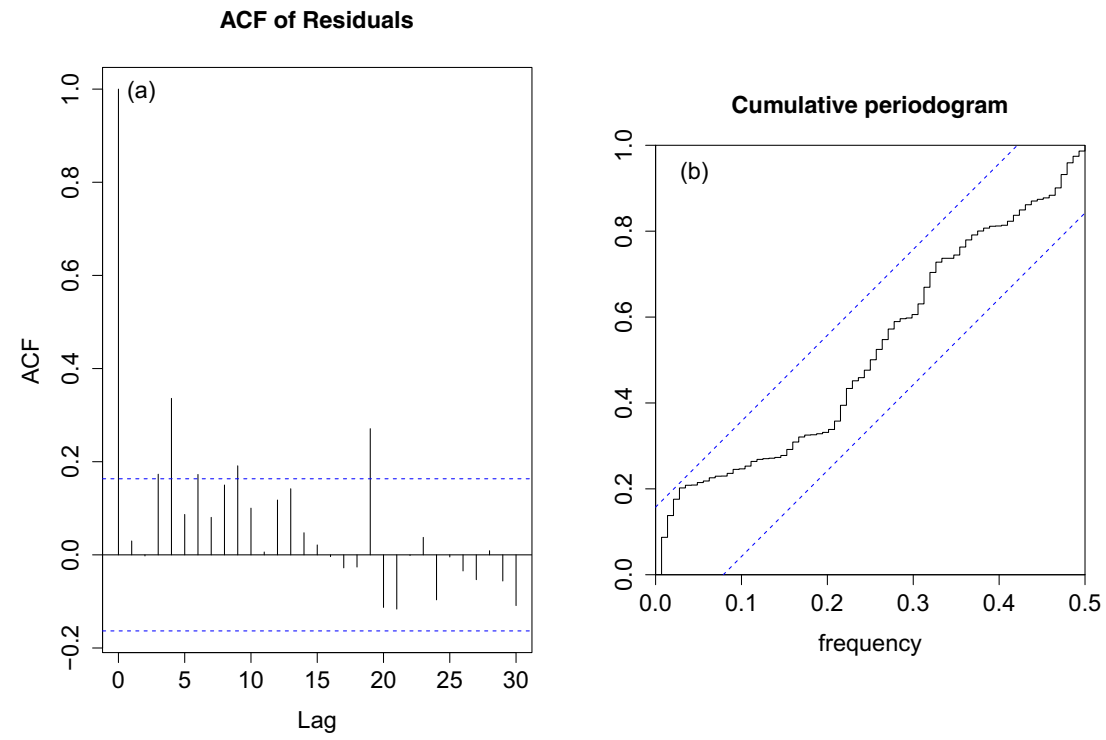

00:00 and 23:50 UTC with 10-min temporal resolution. Measurements include several input values for the CTSM system including $G_{w}, U_{c a n}, T_{a}, T_{c a n}, T_{d e w}$, and $T_{b_{P V}}$. Ground temperature $T_{g}$ in front of the PV module and wall temperature $T_{w}$ behind the PV module have been simulated with the PS scheme in SOLWEIG. $T_{g}$ was averaged over an area of $7.7 \mathrm{~m}^{2}$ (see Figure $\mathrm{S} 1$ in the supplemental material, red square), seen as the distance from the PV module to parked cars. In Fig. 5, we show the white noise verification of the model considering the auto-correlation function (ACF, panel (a)) and the cumulative periodogram (panel (b)). Here, the blue dashed lines mark the confidence level of $95 \%$ under the hypothesis that the model residuals are white noise. The PS describes heat transfer in and around the PV module enough sufficiently. We note in passing that for characterizing a larger PV unit, the model would need to be expanded to a two-state model as used for example by Lodi et al. (2012).

Applying the estimated parameters (Table 1) in Eq. 21 combined with the Euler method, the PV module temperature is predicted. The output of the simulated $\widehat{T}_{b_{P V}}$ is compared with the measured $T_{b_{P V}}$ for 18 to 20 June 2017 in Fig. 6a. In panel (b), we show the difference between model prediction and observations. The model shows most satisfactory results on June 18, a day with partial cloud cover. In contrast, larger differences are found for 19 and 20 June 2017, which have been characterized by prevailing clear-sky conditions. Clear-sky days are more difficult to model due to overall higher temperatures and reflections of obstacles in the environment (see second sun in Figure S3 in the supplemental material). However, the statistical analysis of the CTSM-based system (provided in Fig. 7) shows good agreement throughout the time series, with an explained variance of $R^{2}=0.99$ and a $\mathrm{RMSE}=1.2{ }^{\circ} \mathrm{C}(\mathrm{N}=432)$.

\section{Simulations for various surface conditions}

Urban planning strives to reduce the urban canyon air temperature and generally undesirable effects of the urban heat island. Therefore, the UTCI can describe human thermal comfort inside different surface structures and is thus an important planning quantity.

This study seeks to model the urban thermal environment at a study site in Vienna, Austria. We compare the influence of the current urban structure at the study site (dark asphalt on the ground combined with a glass facade) with those of a ground of bright concrete combined with a

Table 1 Technical specifications of the three PV modules used in this study

\begin{tabular}{|c|c|c|}
\hline \multicolumn{2}{|l|}{ Type of solar cell } & Poly-crystalline $^{1}$ \\
\hline Total aperture area & 0.11 & $\mathrm{~m}^{2}$ \\
\hline Voltage at $\mathrm{MPP}^{2}$ & 16.80 & $\mathrm{~V}$ \\
\hline Current at $\mathrm{MPP}^{2}$ & 0.59 & A \\
\hline Nominal power & 10.00 & $\mathrm{~W}$ \\
\hline PV module efficiency ${ }^{3} \eta_{r e f}$ & 8.07 & $\%$ \\
\hline Temperature coefficient $\beta_{0}$ & 0.50 & $\% \mathrm{~K}^{-1}$ \\
\hline Absorptivity of cell $\alpha_{P V}$ & 0.84 & \\
\hline Emissivity of glass ${ }^{4} \varepsilon_{g l}$ & 0.91 & \\
\hline Transmittance of glass ${ }^{5} \tau_{g l}$ & 0.90 & \\
\hline Emissivity of back side ${ }^{4} \varepsilon_{b_{P V}}$ & 0.85 & \\
\hline Heat capacity $C_{P V}$ & 754.95 & $\mathrm{~J} \mathrm{~K}^{-1}$ \\
\hline
\end{tabular}

${ }^{1} \mathrm{p}-\mathrm{Si}$

${ }^{2}$ Maximum Power Point

${ }^{3}$ Average of all three PV modules

${ }^{4}$ (Armstrong and Hurley 2010)

5 (Herrando et al. 2014) 
Fig. 6 Time series of a the temperature $(T)$ measured inside the urban canyon ( $T_{c a n}$, green) and at the back side of the PV module $\left(T_{b_{P V}}\right.$, blue) and simulated at the back side of the PV module $\left(\widehat{T}_{b_{P V}}\right.$, red) and $\mathbf{b}$ the difference $\left(\Delta T_{b_{P V}}\right)$ between the measured and simulated back-side photovoltaic module temperature
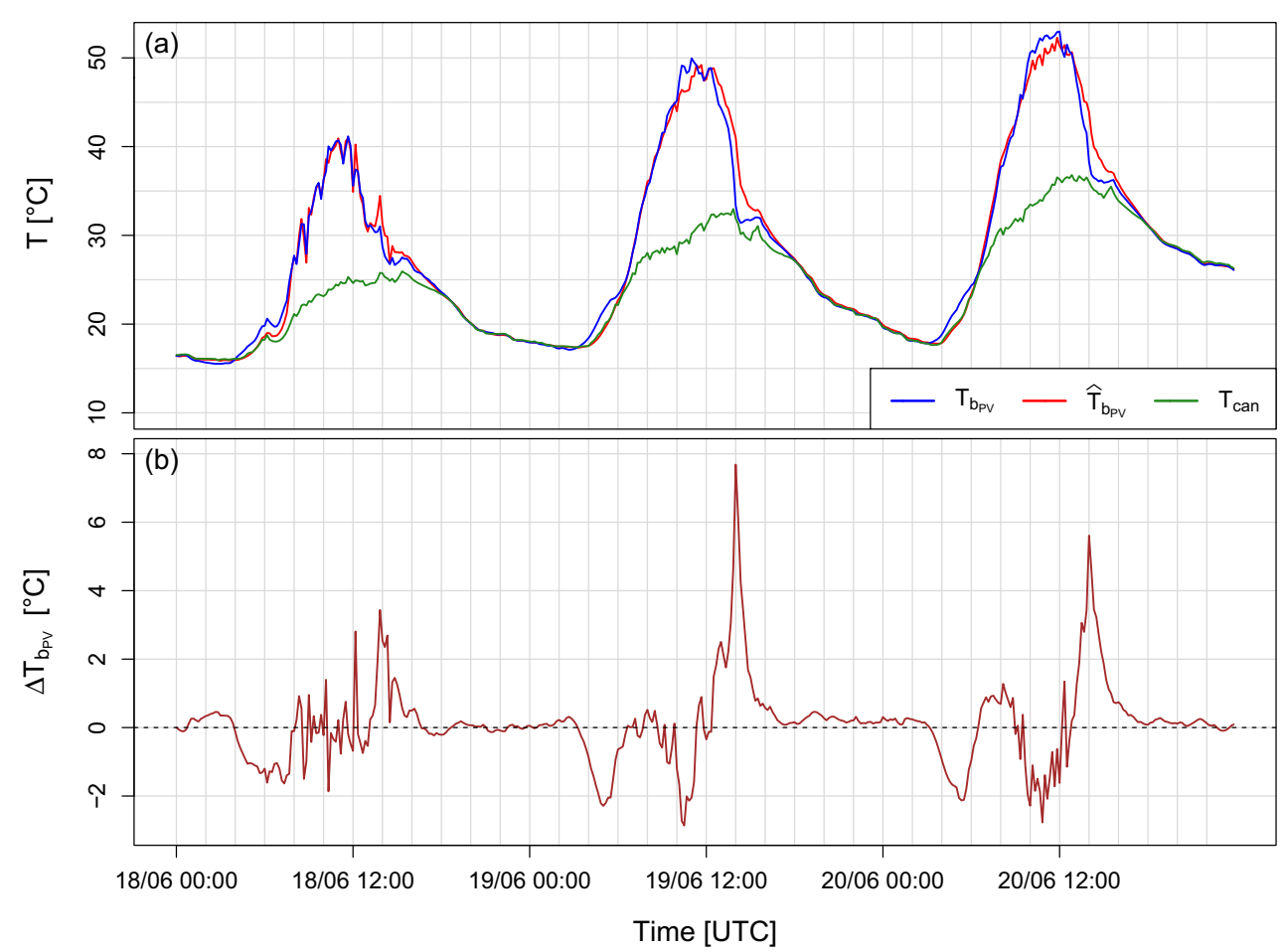

photovoltaic facade. To this aim, we assume conditions where PV modules cover the whole southern wall of the building in the study domain, as the distance between the PV modules and the back-side wall is large enough to assume that the convective heat transfer is the same as used in the CTSM system. The largest uncertainty of this

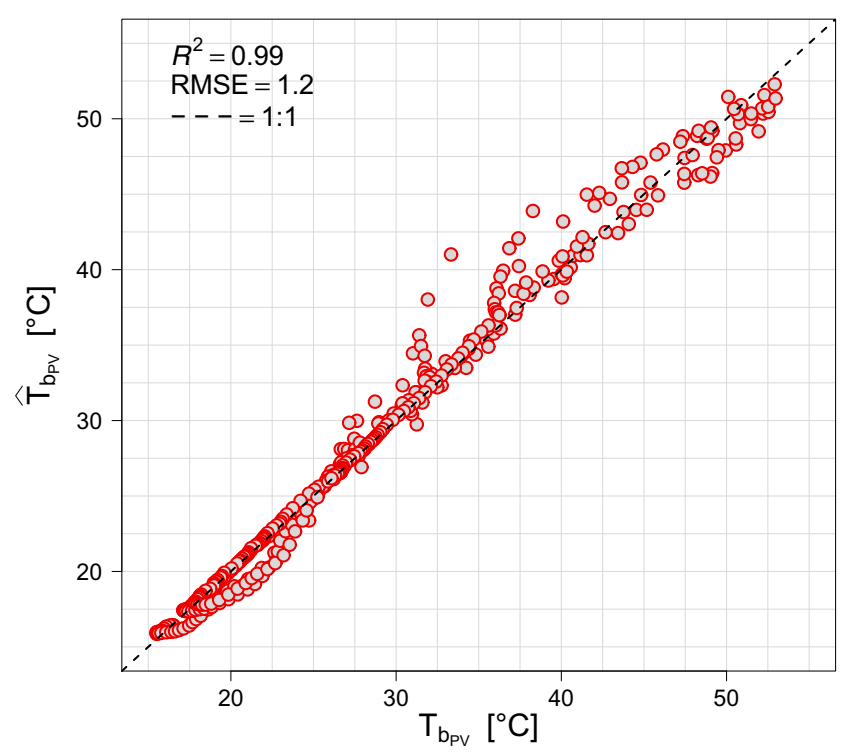

Fig. 7 Scatter plot of the measured temperature $\left(T_{b_{P V}}\right)$ and simulated temperature $\left(\widehat{T}_{b_{P V}}\right)$ of the PV module. The upper-left corner provides the squared Spearman's rank correlation coefficient $\left(R^{2}\right)$ and the root mean square error (RMSE) assumption is that we do not have knowledge about the surface temperature of the back-side wall which is an input variable for thermal radiative heat transfer. Therefore, we need to make assumptions for $T_{w}$. Here, we assume that it can be calculated with the same regression coefficients as given in Fig. $2 \mathrm{~b}$ but considering addition of an average value of $\widehat{T}_{c a n}, T_{a}$, and daily average of $T_{a}$ (considering that the daily average will not change its value, only the amplitude varies). Further, we make the assumption that the calculated $U_{c a n}$ as in the TEB model can be taken as wind speed for calculating the UTCI.

After defining the new modeling systems, a comparison of the canyon air temperature between different surface conditions can be done. For such calculations, the albedo $\kappa$ of each surface has to be defined. The albedo value for asphalt $\kappa_{g}=0.18$ was chosen based on Lindberg et al. (2016). The value for concrete $\kappa_{g}=0.56$ was measured in the work of Krispel et al. (2017) and the value for the PV modules $\kappa_{P V}=0.10$ was taken from Moralejo-Vȧzquez et al. (2015).

Figure $8 \mathrm{a}, \mathrm{b}$, and $\mathrm{c}$ shows time series of $\widehat{T}_{c a n}$ and the UTCI for these different surface conditions including an additional simulation for UTCI with $T_{a}$. The related differences, $\Delta \widehat{T}_{\text {can }}$ and $\Delta$ UTCI, are shown in Fig. 8d, e, and $\mathrm{f}$, respectively. Our results show that a bright ground surface and a slightly decreased wall temperature (see Figures S4 and S5 in the supplemental material) can substantially reduce air temperature (by up to $-1.30{ }^{\circ} \mathrm{C}$ ) and the UTCI (by up to $-1.10^{\circ} \mathrm{C}$ ) in the sun between 7:00 and 14:00 

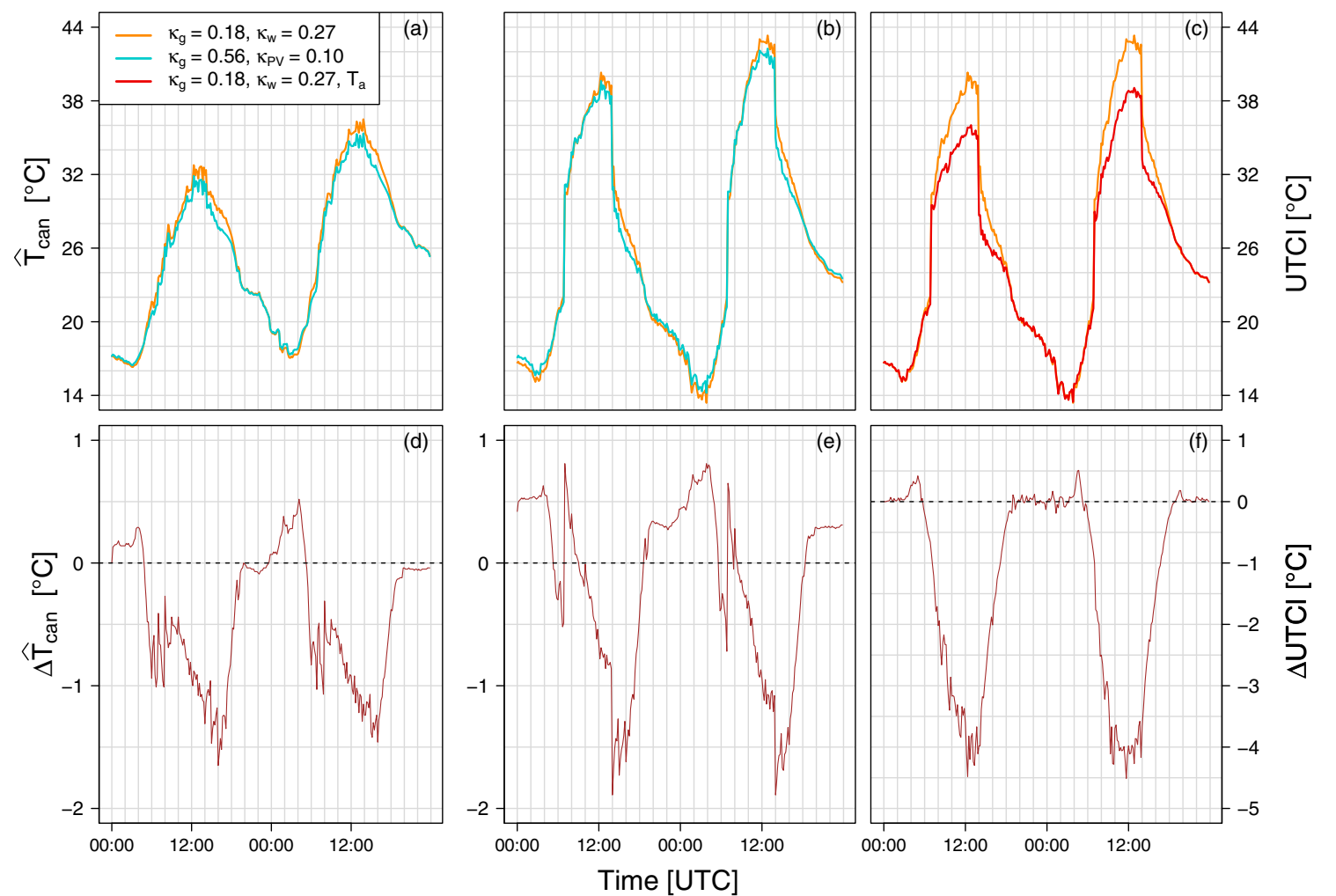

Fig. 8 Time series of a the modeled urban canyon air temperature $\left(\widehat{T}_{\text {can }}\right),(\mathbf{b}, \mathbf{c})$ the modeled Universal Thermal Climate Index (UTCI) with $\widehat{T}_{\text {can }}$ (orange and cyan), and the air temperature measured at the rooftop $T_{a}$ (red) between 19 and 20 June 2017. The legend in panel a shows the reflectance $(\kappa)$ for different surfaces $\left(\kappa_{g}=0.18\right.$ for

UTC. Even larger reductions are found in the shade between 14:00 and 16:00 UTC for both canyon air temperature (by up to $-1.65^{\circ} \mathrm{C}$ ) and UTCI (by up to $-1.85{ }^{\circ} \mathrm{C}$ ). Further, Fig. 8f shows that an air temperature measured at a site which is not related to the actual surrounding surfaces results in a highly erroneous estimate of thermal (dis)comfort. In our case, $\triangle \mathrm{UTCI}$ simulated with $T_{a}$ shows a difference up to $-4.50{ }^{\circ} \mathrm{C}$ and misses the very strong occurring heat stress (defined as UTCI between 38 and $46^{\circ} \mathrm{C}$ ) on the first day of the simulation period (see Fig. 8c).

These results indicate that even small, local changes to the surface and thus albedo can have a measurable effect on air temperature and UTCI in an urban canyon. While this decrease between -1 and $-2{ }^{\circ} \mathrm{C}$ seems to be noticeable but yet small, it shall not be underestimated in its effect on human comfort in a warmer future climate.

\section{Discussion and conclusions}

This study seeks to improve the simulation of air temperature in urban canyons. To this aim, field measurements have been performed in 2016 and 2017, to evaluate/update asphalt, $\kappa_{w}=0.27$ for glass facade, $\kappa_{g}=0.56$ for concrete, and $\kappa_{P V}=0.10$ for photovoltaic facade). Panels $\mathbf{d}, \mathbf{e}$, and $\mathbf{f}$ provide the difference between each surface condition regarding $\widehat{T}_{\text {can }}$ and UTCI, respectively

the wall and ground temperature parameterization and an energy balance model for photovoltaic (PV) modules within the solar and long-wave environmental irradiance geometry (SOLWEIG) model and couple it with parts of the Town Energy Balance (TEB) model.

For the parameterization of the wall surface temperature, we take infrared pictures of the Schwackhöfer-Haus at the University of Natural Resources and Life Sciences (BOKU), Vienna, with a FLIR E60bx to evaluate the accuracy of the current calculation scheme in SOLWEIG. Results show a clear overestimation of the surface temperature at solar elevation angles over $56^{\circ}\left(R^{2}=0.61\right)$. We use global radiation measurements on a vertical plane instead to generate new regression coefficients $\left(R^{2}=0.76\right)$.

We implement an updated calculation scheme for simulating ground temperature, which allows considering surface with user-specified albedo value and thermal conductivity properties. To develop this scheme, we used the force-restore method combining the radiation, sensible, and ground heat flux with the Euler method to estimate a time series of the ground temperature.

At the BOKU site, the ambient air temperature has been measured routine at the rooftop (26-m height above ground) 
but outputs show a difference up to $6{ }^{\circ} \mathrm{C}$ to the measured canyon air temperature ( $3 \mathrm{~m}$ height above ground). This huge difference is compensated with parts of the TEB model calculating the canyon air temperature.

We compare the performance of the currently implemented SOLWEIG scheme (CS) and the here-proposed calculation scheme (PS). The results of the canyon air temperature show a better performance of PS, particularly a substantial reduction in RMSE. While the PS shows generally satisfactory skill in predicting temperatures inside the studied urban canyon, we note that further updates are needed for the representation of open areas, street crossings, and different canyon orientations. Further, an implementation of the glazing ratio for buildings would also increase the overall quality of SOLWEIG.

Considering the importance of sustainable energy production and climate warming, we perform scenario calculations to investigate effects of potential changes to the wall surface inside an urban canyon. We do so by evaluating a heat transfer single-state model for a vertically mounted photovoltaic (PV) module.

A comparison between model results for current surface conditions (dark asphalt on the ground combined with a glass facade) and possible modification conditions (ground covered with bright concrete and a PV facade) was performed. The results indicate a robust decrease in canyon air temperature by up to $-1.65^{\circ} \mathrm{C}$ for the modified canyon environment. To estimate human thermal comfort, we focus to calculate the Universal Thermal Climate index (UTCI). UTCI decreases by approx. $-1.00{ }^{\circ} \mathrm{C}$ in the sun and $-1.85^{\circ} \mathrm{C}$ in the shade considering a change from present to modified conditions. We note in passing that future work should focus on effects of brighter surfaces for potentially increased human thermal stress.

We note in closing that additional field experiments for PV facades or building-integrated PV systems on large scales (e.g., a size of $60 \cdot 20 \mathrm{~m}^{2}$ like the south-facing wall of the Schwackhöfer-Haus) would strongly increase the quality of energy balance models, as the one presented here, and the possibility to mitigate, at least partially, urban heat island effects.

Acknowledgements Open access funding provided by University of Natural Resources and Life Sciences Vienna (BOKU). The authors thank Meteo France and Valéry Masson for providing the Town Energy Balance model. The authors are grateful to Christian Gützer (University of Natural Resources and Life Sciences (BOKU), Vienna) for the technical support. This work received financial support from the University of Natural Resources and Life Sciences (BOKU) in Vienna.

Funding information This work was supported by the project "Optimizing reflecting materials and photovoltaics in urban areas regarding the radiation balance and bioclimatic" funded by the Austrian Research Promotion Agency (FFG) and the project "Influence of urban expansions on the urban heat island in Vienna" funded by the Klimaund Energiefonds.

Abbreviations $a$, time-of-day dependent factor (force-restore method) $(1 / \mathrm{s}) ; A$, area $\left(\mathrm{m}^{2}\right) ; B$, day of the year dependent factor (declination angle) (-); $c$, specific heat capacity $(\mathrm{J} /) ; C$, heat capacity $(\mathrm{J} / \mathrm{K}) ; C_{d}$, drag coefficient (-); CS, currently implemented SOLWEIG scheme; CTSM, continuous time stochastic model; $e$, Gaussian white noise (-); $f$, non-linear function; $F$, net radiation balance $\left(\mathrm{W} / \mathrm{m}^{2}\right) ; g$, gravitational constant $\left(\mathrm{m} / \mathrm{s}^{2}\right) ; G$, global radiation $\left(\mathrm{W} / \mathrm{m}^{2}\right) ; h$, building height $(\mathrm{m})$; $\bar{h}$, average building height $(\mathrm{m}) ; H$, heat flux $\left(\mathrm{W} / \mathrm{m}^{2}\right) ; i$, value for the size of every step (Euler method) (-); IAM, incidence angle modifier $(-) ; M$, non-linear function; $n$, day of the year $(-) ; N$, number of observations (-); $p$, pressure (hPa); PS, proposed calculation scheme; $Q$, heat transfer $\left(\mathrm{W} / \mathrm{m}^{2}\right) ; Q c$, convective heat transfer $\left(\mathrm{W} / \mathrm{m}^{2}\right) ; Q l$, long-wave heat transfer $\left(\mathrm{W} / \mathrm{m}^{2}\right) ; R E S$, aerodynamic resistance $(\mathrm{s} / \mathrm{m})$; $R H$, relative humidity $(\%) ; S$, soil heat capacity $\left(\mathrm{J} / \mathrm{m}^{3} \mathrm{~K}\right) ; t$, time (s); $T$, measured temperature $\left({ }^{\circ} \mathrm{C}\right) ; \hat{T}$, modeled temperature $\left({ }^{\circ} \mathrm{C}\right) ; u_{*}+w_{*}$, turbulent wind $(\mathrm{m} / \mathrm{s}) ; U$, wind speed $(\mathrm{m} / \mathrm{s}) ; w$, street width $(\mathrm{m}) ; W$, nonlinear function; $y$, discrete time observation; $z$, depth of thermal layer $(\mathrm{m}) ; z_{0}$, roughness length $(\mathrm{m})$.

Greek symbols $\alpha$, absorptivity (-); $\beta$, tilt angle of a vertical plane from the horizontal $\left(^{\circ}\right) ; \beta_{0}$, temperature coefficient of photovoltaic module $(\% / \mathrm{K}) ; \delta$, declination angle $\left({ }^{\circ}\right) ; \Delta T$, temperature difference $(\mathrm{K}) ; \varepsilon$, emissivity $(-) ; \eta$, photovoltaic module efficiency $(\%)$; $\theta_{a o i}$, angle of incidence $\left({ }^{\circ}\right) ; \Theta$, vector of unknown parameters; $\kappa$, reflectance (-); $\lambda$, thermal conductivity $(\mathrm{W} /(\mathrm{m} \mathrm{K})) ; \rho$, material density $(\mathrm{kg} / \mathrm{m} \hat{A} s ̧) ; \sigma$, Stefan-Boltzmann constant $\left(\mathrm{W} /\left(\mathrm{m}^{2} \mathrm{~K}^{4}\right)\right) ; \Sigma$, covariance; $\Upsilon$, time series of $\mathrm{N}$ observations; $\phi$, geographical latitude $\left({ }^{\circ}\right)$; $\Psi$, view factor (-); $\omega$, Wiener processs; $\Omega$, Earth's angle velocity $(1 / \mathrm{s})$.

Subscripts $a$, air; as, near-surface air; asphalt, index for asphalt properties; $b$, back side; $b_{P V}$, back side of photovoltaic module; $c$, combined value; can, urban canyon; dew, dew point; $e$, electricity; $f$, front side; $g$, ground; $g l$, glass; $h$, horizontal plane; $m$, approximately constant value; $p$, constant pressure; $P V$, photovoltaic module; $r$, rate; ref, reference; $s$, solar; sky, sky; top, rooftop; $w$, wall.

Open Access This article is distributed under the terms of the Creative Commons Attribution 4.0 International License (http:// creativecommons.org/licenses/by/4.0/), which permits unrestricted use, distribution, and reproduction in any medium, provided you give appropriate credit to the original author(s) and the source, provide a link to the Creative Commons license, and indicate if changes were made.

\section{References}

Armstrong S, Hurley WG (2010) A thermal model for photovoltaic panels under varying atmospheric conditions. Appl Therm Eng 30(11-12):1488-1495

Arya P (ed.) (2001) Introduction to micrometeorology, Academic Press

Barker G, Norton P (2003) Building america system performance test practices: part 1 - photovoltaic systems, technical report, Office of Scientific and Technical Information (OSTI)

Blackadar AmKa (1976) Modeling the nocturnal boundary layer, Reprints third symp. Atmospheric turbulence, diffusion and air quality, Raleigh, Am Meteorol Soc, pp 46-49

Blazejczyk K, Epstein Y, Jendritzky G, Staiger H, Tinz B (2011) Comparison of UTCI to selected thermal indices. Int J Biometeorol 56(3):515-535 
Bogren J, Gustavsson T, Karlsson M, Postgard U (2000) The impact of screening on road surface temperature. Meteorlogical Applications 7(2):97-104

Brito MC, Freitas S, Guimarães S, Catita C, Redweik P (2017) The importance of facades for the solar PV potential of a mediterranean city using liDAR data. Renew Energy 111:85-94

Bröde P, Fiala D, Błażejczyk K, Holmér I, Jendritzky G, Kampmann B, Tinz B, Havenith G (2011) Deriving the operational procedure for the universal thermal climate index (utci). Int J Biometeorol 56(3):481-494

Duffie JA, Beckman WA (2013) Solar engineering of thermal processes. Wiley, New York

Fiala D, Lomas KJ, Stohrer M (2001) Computer prediction of human thermoregulatory and temperature responses to a wide range of environmental conditions. Int J Biometeorol 45(3):143159

FLIR Systems Inc. (2016) http://www.flir.com

Grimmond CSB, Blackett M, Best MJ, Barlow J, Baik J-J, Belcher SE, Bohnenstengel SI, Calmet I, Chen F, Dandou A et al (2010) And The international urban energy balance models comparison project: first results from phase 1. J Appl Meteorol Climatol 49(6): 1268-1292

Herrando M, Markides CN, Hellgardt K (2014) A UK-based assessment of hybrid PV and solar-thermal systems for domestic heating and power: system performance. Appl Energy 122:288 309

Jazwinski AH (1970) Stochastic processes and filtering theory, Elsevier, pp vii-viii

Jones AD, Underwood CP (2001) A thermal model for photovoltaic systems. Sol Energy 70(4):349-359

Juhl R (2016) Ctsmr: Ctsm for r. R package version 0.6.10

Juhl R, Moller J, Madsen H (2016) ctsmr - continuous time stochastic modeling in $\mathrm{r}$, The $\mathrm{R}$ Journal

King DL, Boyson WE, Kratochvil JA (2004) Photovoltaic array performance model, http://energy.sandia.gov/download/21046/

Kotak Y, Gul MS, Muneer T, Ivanova SM (2015) Investigating the impact of ground albedo on the performance of pv systems

Krispel S, Peyerl M, Maier G, Weihs P (2017) Urban heat islands reduktion von innerstädtischen wärmeinseln durch whitetopping. Bauphysik 39(1):33-40

Lindberg F, Grimmond CSB, Gabey A, Huang B, Kent CW, Sun T, Theeuwes NE, Järvi L, Ward HC, Capel-Timms I (2018) Urban multi-scale environmental predictor (umep): an integrated tool for city-based climate services. Environ Model Softw 99:7087

Lindberg F, Grimmond CSB (2011) The influence of vegetation and building morphology on shadow patterns and mean radiant temperatures in urban areas: model development and evaluation. Theor Appl Climatol 105(3-4):311-323
Lindberg F, Grimmond CSB (2016) Solweig, http://urban-climate.net/ umep/SOLWEIG

Lindberg F, Holmer B, Thorsson S (2008) SOLWEIG 1.0 modelling spatial variations of $3 \mathrm{~d}$ radiant fluxes and mean radiant temperature in complex urban settings. Int J Biometeorol 52(7):697-713

Lindberg F, Jonsson P, Honjo T, Wästberg D (2015) Solar energy on building envelopes - $3 \mathrm{~d}$ modelling in a $2 \mathrm{~d}$ environment. Sol Energy 115:369-378

Lindberg F, Onomura S, Grimmond CSB (2016) Influence of ground surface characteristics on the mean radiant temperature in urban areas. Int J Biometeorol 60(9):1439-1452

Lodi C, Bacher P, Cipriano J, Madsen H (2012) Modelling the heat dynamics of a monitored test reference environment for building integrated photovoltaic systems using stochastic differential equations. Energy and Buildings 50:273-281

Lumitos GmbH (2017) http://www.chemie.de/

Masson V (2000) A Physically-based scheme for the urban energy budget in atmospheric models. Bound-Layer Meteorol 94(3):357397

Moigne PL (2012) Surfex scientific documentation

Moralejo-Vàzquez FJ, Martín-chivelet N, Olivieri L, Caamaño-martín E (2015) Luminous and solar characterization of PV modules for building integration. Energy and Buildings 103:326-337

Nielsen JN, Madsen H, Young PC (2000) Parameter estimation in stochastic differential equations: an overview. Annu Rev Control 24:83-94

Palyvos JA (2008) A survey of wind convection coefficient correlations for building envelope energy systems' modeling. Appl Therm Eng 28(8-9):801-808

PVEducation (2017) http://pvcdrom.pveducation.org/SUNLIGHT/ MODTILT.HTM

Sharples S (1984) Full-scale measurements of convective energy losses from exterior building surfaces. Build Environ 19(1):31-39

Spencer JW (1971) http://www.mail-archive.com/sundial@uni-koeln. $\mathrm{de} / \mathrm{msg} 01050 . \mathrm{html}$

Stull RB (ed.) (1988) An introduction to boundary layer meteorology, Springer Netherlands

UN (2014) World urbanization prospects, United Nations. visited on https://esa.un.org/unpd/wup/Publications/Files/WUP2014-High lights.pdf

Weihs P, Staiger H, Tinz B, Batchvarova E, Rieder H, Vuilleumier L, Maturilli M, Jendritzky G (2011) The uncertainty of UTCI due to uncertainties in the determination of radiation fluxes derived from measured and observed meteorological data. Int $\mathrm{J}$ Biometeorol 56(3):537-555

ZAMG HoheWarte (2018) Meteorological measurements, data set from 1981 to 2017, Central Institution for Meteorology and Geodynamics 